\title{
Pollakiuria and its relationship with obsessive compulsive disorder
}

\author{
Parsa Yousefichaijan ${ }^{1}$, Bahman Salehi $^{2}$, Ali Khosrobeigi ${ }^{3 *}$, Melika Hajirahimi $^{3}$, Mohammad Rafiei $^{4}$, \\ Hassan Taherahmadi ${ }^{1}$, Fakhreddin Shariatmadari ${ }^{1}$, Ali Arjmand ${ }^{1}$ \\ ${ }^{1}$ Department of Pediatrics, Arak University of Medical Sciences, Arak, Iran \\ ${ }^{2}$ Department of Psychiatry, Arak University of Medical Sciences, Arak, Iran \\ ${ }^{3}$ Students Research Committee, Arak University of Medical Sciences, Arak, Iran \\ ${ }^{4}$ Department of Biostatics, Arak University of Medical Sciences, Arak, Iran
}

\section{A R T I C L E I N F O}

Article Type:

Brief Communication

\section{Article History:}

Received: 20 April 2017

Accepted: 10 August 2017

Published online: 28 August 2017

\section{Keywords:}

Child

Obsessive-Compulsive disorder

Pollakiuria

\begin{abstract}
A B S T RA C T
Introduction: Some children have a severe urinary frequency with an abrupt onset. They void every 15 minutes during the day, without daytime incontinence, dysuria, nocturia, or urinary tract infection (UTI). Pollakiuria or daytime frequency syndrome of children is the term used to describe this condition.

Objectives: This study was designed to evaluation and correlation between obsessivecompulsive disorder (OCD) and day time frequency syndrome.

Patients and Methods: In this study, we selected 76 children with pollakiuria as the case group and 76 healthy children for the control group in Arak, Iran. The diagnosis of obsessivecompulsive disorder was conducted through interviews, OCI-CV tests, and the psychiatrist's approval. The comparison was based on DSM-IV-TR diagnostic criteria. The analysis was conducted by SPSS version 16 and a $P$ value less than 0.05 was considered significant.

Results: The obsessive disorder was noted in five individuals (6.6\%) of case group (pollakiuria) and eight individuals (10.5\%) of the control group $(P=0.282)$.

Conclusion: The results of this study showed that OCD is not more common in children with pollakiuria
\end{abstract}

Implication for health policy/practice/research/medical education:

In a study on 76 children with pollakiuria as the case group and 76 healthy children, OCD is not more common in children with pollakiuria.

Please cite this paper as: Yousefichaijan P, Salehi B, Khosrobeigi A, Hajirahimi M, Rafiei M, Taherahmadi H, et al. Pollakiuria and its relationship with obsessive compulsive disorder. J Renal Inj Prev. 2018;7(1):35-37. DOI: 10.15171/jrip.2018.08.

\section{Introduction}

Some children have a severe urinary frequency with an abrupt onset. They void every 15 minutes during the day, without daytime incontinence, dysuria, nocturia, or urinary tract infection (UTI). These symptoms are most common in children between 4 and 6 years old. Additionally this disorder is more common in boys. Pollakiuria or daytime frequency syndrome of children is the term used to describe this condition. No anatomic problem is detected in the child, as it is a functional disorder. The symptoms often occur before the child starts preschool, or if the child undergoes family stress (1-3). The symptoms mostly start before school age. These children should be evaluated regarding presence of UTI.
The physicians should ensure the child empties his/her bladder reasonably. Sometimes, pinworms can also cause these symptoms. This is a self-limiting condition that gets resolved in 2 to 3 months. The administration of an anticholinergic agent has rarely been effective (4-6).

Obsessive compulsive disorder is a chronic disabling sickness characterized $(7,8)$. Cleaning compulsions and washing are common in children $(9,10)$. Very few studies have assessed the association between pollakiuria and obsessive-compulsive disorder (OCD) (11-14).

\section{Objectives}

This study was designed to evaluation and correlation between OCD and day time frequency syndrome. 


\section{Patients and Methods}

In this study, we selected 76 children with pollakiuria in the case group and 76 healthy children in the control group. The study was conducted in Amir-Kabir hospital, Arak, Iran. The exclusion criteria were; 1) children with psychological disorders and/or mental retardation or nervous system disorders. 2) Children whose parents did not cooperate fully-for example, did not fill the forms completely. The children of the control group were selected from pediatrics with UTI and normal DMSA renal scan, kidney sonography, and voiding cystourethrogram (VCUG). The diagnosis of OCD was conducted through interviews, OCI-CV tests, and the psychiatrist's approval. The comparison was based on DSM-IV-TR diagnostic criteria $(15,16)$.

\section{Ethical issues}

The research followed the tenets of the Declaration of Helsinki; informed consent was obtained; and the research was approved by the ethical committee of Arak University of Medical Sciences (\#92-146-8).

\section{Statistical analysis}

Results were analyzed using descriptive statistics and chisquare test. The analysis was conducted by SPSS version 16 and a $P$ value less than 0.05 was considered significant.

\section{Results}

Overall, 152 children (76 as a case group and 76 as a control group) were selected for our study. The demographic factors were studied and matched in 2 groups. The average of age in children in the case and control teams was calculated at $8.13 \pm 1.39$ years and $8.19 \pm 2.026$ years (Table $1)$. The obsessive disorder was noted in $5(6.6 \%)$ of case group (pollakiuria) and $8(10.5 \%)$ of control group $(P=$ 0.282) (Table 2).

\section{Discussion}

In this study, we compared OCD in children with and without pollakiuria. To the best of our knowledge, this is the first study that has studied OCD in children with

Table 1. Mean of children age

\begin{tabular}{llll}
\hline Age & Frequency & Mean & $P$ value \\
\hline Case & 76 & $8.13 \pm 1.39$ & 0.816 \\
Control & 76 & $8.19 \pm 2.02$ & \\
\hline
\end{tabular}

Table 2. Frequency of OCD in children

\begin{tabular}{|c|c|c|c|}
\hline \multirow{2}{*}{ Group } & \multicolumn{2}{|c|}{ OCD } & \multirow[b]{2}{*}{ Total } \\
\hline & Yes & No & \\
\hline \multirow{2}{*}{ Case, No. (\%) } & 5 & 71 & 76 \\
\hline & 6.6 & 93.4 & 100 \\
\hline \multirow{2}{*}{ Control, No. (\%) } & 8 & 68 & 76 \\
\hline & 10.5 & 89.5 & 100 \\
\hline \multirow{2}{*}{ Total, No. (\%) } & 13 & 139 & 152 \\
\hline & 8.6 & 91.4 & 100 \\
\hline
\end{tabular}

pollakiuria.

The distribution of obsession in children showed no meaningful relationship between OCD disorder and urination frequency disorders.

Koff et al reported that dysfunctional elimination syndromes are associated with late reflux disappearing and an increase in urinary infection (14).

Mota et al highlighted that wrong training may be a causative factor for bladder and intestinal disorders (17). Fonseca et al pointed out a high prevalence of lower urinary tract symptoms in children with nocturia. They found the association of nocturia with other urinary symptoms was usual (18).

\section{Conclusion}

In our study we found no definite relationship between obsession and urinary disorders. However, this study requires more investigation. Similar studies with a higher proportion of samples at different centers are recommended in order to help these patients.

\section{Limitations of study}

Low proportion of patients is a limitation of our study.

\section{Authors' contribution}

Study concept and design; PY. Acquisition of data and sampling; PY, BS, HT, AA and FS. Analysis and interpretation of data; PY and AK. Drafting of the manuscript; $\mathrm{AK}$ and $\mathrm{MH}$. Critical revision of the manuscript for important intellectual content; PY, AK and MH. Statistical analysis; MR. Study supervision; PY and AK.

\section{Conflicts of interest}

The authors declare no conflict of interest.

\section{Ethical considerations}

Ethical issues (including plagiarism, data fabrication, double publication) have been completely observed by the authors.

\section{Funding/Support}

This project was financially supported by vice chancellor for research of Arak University of Medical Sciences (Grant \#915).

\section{References}

1. Yousefi P, Salehi B, Rafeie M, Firouzifar M, Mousavinejad SA. Parents function and behavioral disorders in children with and without diurnal voiding dysfunction: A comparative study. Zahedan J Res Med Sci 2014;16:1-4.

2. Yousefichaijan P, Salehi B, Khosrobeigi A, Hajirahimi M, Rafiei M, Taherahmadi M. Prevalence of obsessivecompulsive disorder in pediatric patients with the daytime frequency syndrome of childhood or pollakiuria. Arak Med Uni J. 2014;17:80-7.

3. Yousefichaijan P, Khosrobeigi A, Salehi B, Taherahmadi H, Shariatmadari F, Ghandi Y, Alinejad S, Farhadiruzbahani F. Incidence of obsessive-compulsive disorder in children 
with nonmonosymptomatic primary nocturnal enuresis. J Pediatr Neurosci. 2016;11:197-9. doi: 10.4103/18171745.193371

4. Yousefi P, Firouzifar M, Cyrus A. Correlation between sacral ratio and primary enuresis. J Nephropathol. 2012; 1:183-7. doi: 10.5812/nephropathol.8120.

5. Yousefichaijan P, Khosrobeigi A, Taherahmadi H, Soltani M, Ghandi Y, Shariatmadari F, et al. Assessment of Blood Pressure in Primary Monosymptomatic Nocturnal Enuresis. J Pediatr Nephrol. 2016;4:33-6.

6. Yousefichaijan P, Salehi B, Rafiei M, Taherahmadi H, Sharafkhah M, Naziri M. Prevalence of obsessivecompulsive disorder in pediatric and adolescent patients with chronic kidney disease. J Pediatr Nephrol. 2014;2:1079.

7. Yousefichaijan P, Salehi B, Rafiei M, Ghadimi N, Taherahmadi H, Hashemi SM, et al. Emotional disorders in children with monosymptomatic primary nocturnal enuresis. J Pediatr Nephrol. 2015;3:22-5.

8. Joshi G, Wozniak J, Petty C, Vivas F, Yorks D, Biederman J, Geller D. Clinical characteristics of comorbid obsessivecompulsive disorder and bipolar disorder in children and adolescents. Bipolar Disord. 2010;12:185-95. doi: 10.1111/j.1399-5618.2010.00795.x.

9. Riddle MA. Obsessive-compulsive disorder in children and adolescents. CNS Spectrums. 1998; 3:21-3.

10. Tükel R, Ertekin E, Batmaz S, Alyanak F, Sözen A, Aslantaş $B$, et al. Influence of age of onset on clinical features in obsessive-compulsive disorder. Depression and anxiety. 2005;21:112-7. doi: 10.1002/da.20065.

11. Mataix-Cols D, Nakatani E, Micali N, Heyman I. Structure of obsessive-compulsive symptoms in pediatric OCD. J Am Acad Child Adolesc Psychiatry. 2008;47:773-8. doi:
10.1097/CHI.0b013e31816b73c0

12. Storch EA, Milsom VA, Merlo LJ, Larson M, Geffken GR, Jacob ML, et al. Insight in pediatric obsessive-compulsive disorder: associations with clinical presentation. Psychiatry Res. 2008;160:212-20. doi: 10.1016/j.psychres.2007.07.005.

13. Flament MF, Whitaker A, Rapoport JL, Davies M, Berg CZ, Kalikow K, et al. Obsessive compulsive disorder in adolescence: an epidemiological study. J Am Acad Child Adolesc Psychiatry. 1988;27:764-71. doi: 10.1097/00004583198811000-00018

14. Koff SA, Wagner TT, Jayanthi VR. The relationship among dysfunctional elimination syndromes, primary vesicoureteral reflux and urinary tract infections in children. J Urol. 1998;160:1019-22.

15. Yousefi Chaijan P, Salehi B, Khosrobeigi A, Hajirahimi M, Rafiei M, Taher Ahmadi H. Prevalence of obsessivecompulsive disorder in pediatric patients with the daytime frequency syndrome of childhood or pollakiuria. Arak Med Uni J. 2014;17:80-6.

16. Yousefichaijan P, Sharafkhah M, Rafeie M, Salehi B. Obsessive Compulsive Inventory-Child Version (OCV$\mathrm{CI}$ ) to evaluate obsessive compulsive disorder in children with early stages of chronic kidney disease: a case control study. Nephrourol Mon. 2016;8:e34017. doi: 10.5812/ numonthly.34017.

17. Mota DM, Barros AJ. Toilet training: methods, parental expectations and associated dysfunctions. J Pediatr (Rio J). 2008;84:9-17. doi: 10.2223/JPED.1752.

18. Fonseca EG, Bordallo AP, Garcia PK, Munhoz C, Silva CP. Lower urinary tract symptoms in enuretic and nonenuretic children. J Urol. 2009;182:1978-83. doi: 10.1016/j. juro.2009.04.083.

Copyright (c) 2018 The Author(s); Published by Nickan Research Institute. This is an open-access article distributed under the terms of the Creative Commons Attribution License (http://creativecommons.org/licenses/by/4.0), which permits unrestricted use, distribution, and reproduction in any medium, provided the original work is properly cited. 